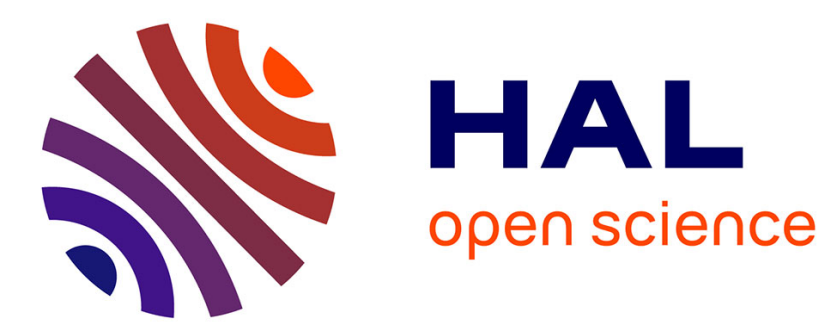

\title{
Shaping the Electrocatalytic Performance of Metal Complexes for CO2 Reduction
}

\author{
Philipp Gotico, Winfried A Leibl, Zakaria Halime, Ally Aukauloo
}

\section{To cite this version:}

Philipp Gotico, Winfried A Leibl, Zakaria Halime, Ally Aukauloo. Shaping the Electrocatalytic Performance of Metal Complexes for CO2 Reduction. ChemElectroChem, In press, 10.1002/celc.202100476 . hal-03279622

\section{HAL Id: hal-03279622 \\ https://hal.science/hal-03279622}

Submitted on 6 Jul 2021

HAL is a multi-disciplinary open access archive for the deposit and dissemination of scientific research documents, whether they are published or not. The documents may come from teaching and research institutions in France or abroad, or from public or private research centers.
L'archive ouverte pluridisciplinaire HAL, est destinée au dépôt et à la diffusion de documents scientifiques de niveau recherche, publiés ou non, émanant des établissements d'enseignement et de recherche français ou étrangers, des laboratoires publics ou privés. 


\title{
Shaping the Electrocatalytic Performance of Metal Complexes for $\mathrm{CO}_{2}$ Reduction
}

\author{
Philipp Gotico, ${ }^{[a, \S]}$ Winfried Leibl, ${ }^{[a]}$ Zakaria Halime,${ }^{[b]}$ and Ally Aukauloo*[a,b] \\ Tribute to Pr. Jean-Michel Savéant \\ [a] Dr: P. Gotico, Dr. W. Leibl, Prof. A. Aukauloo \\ Université Paris-Saclay, CEA, CNRS, Institute for Integrative Biology of the Cell (I2BC) \\ 91198 Gif-sur-Yvette, France \\ $\S$ Current Affiliation: Helmholtz-Zentrum Berlin für Materialien und Energie, 14109 Berlin, Germany \\ [b] Dr. Z. Halime, Prof. A. Aukauloo \\ Université Paris-Saclay, CNRS, Institut de chimie moléculaire et des matériaux d'Orsay (ICMMO) \\ 91405 Orsay, France \\ E-mail: ally.aukauloo@universite-paris-saclay.fr
}

\begin{abstract}
The mass scale catalytic transformation of carbon dioxide $\left(\mathrm{CO}_{2}\right)$ into reduced forms of carbon is an imperative to address the ever-increasing anthropogenic emission. Understanding the mechanistic routes leading to the multi-electron-proton conversion of $\mathrm{CO}_{2}$ provides handles for chemists to overcome the kinetically and thermodynamically hard challenges and further optimize these processes. Through extensive electrochemical investigations, Prof. J-M. Savéant and coworkers have made accessible to chemists invaluable electro-analytical tools to address and position the electrocatalytic performance of molecular catalysts grounded on a theoretical basis. Furthermore, he has bequeathed lessons to future generations on ways to improve the catalytic activity and on the electrocatalytic zone we must target. As a tribute to his accomplishments, we recall here a few aspects on the tuning of iron porphyrin catalysts by playing on electronic effects, proton delivery, hydrogen bonding and electrostatic interactions and its implications to other catalytic systems.
\end{abstract}

\section{Introduction}

Photosynthesis is the process that uses sunlight as sole energy input to flush carbon dioxide $\left(\mathrm{CO}_{2}\right)$ from our atmosphere and convert it into a chemical energy vector. Chemists worldwide are devoting much effort to develop molecules and materials for solar fuel production, closing in on an economy driven by carbon-neutral energy supplies. The enormous challenges are to develop advanced materials that can capture light to activate and transform very stable molecules i.e., water and carbon dioxide, the key ingredients, into new molecules for our needs. As it goes in science, we stand on the shoulders of giants to pursue the still unsolved problems and bring new knowledge to relay with the coming generations of scientists. Prof. JeanMichel Savéant ${ }^{[1]}$ was one of these giants whose scientific contributions will ripple to future young minds. In this contribution, we will focus on some facets on the development of molecular catalysts based on the ubiquitous tetrapyrrole macrocycle, the porphyrins, also nicknamed as the "molecule of life" by A. Battersby. ${ }^{[2]}$ Metalloporphyrin models have been under much investigation for both reductive and oxidative activation of small molecules. ${ }^{[3]}$ This being so, primarily because of their involvement in natural systems performing such processes. Metalloporphyrin-containing enzymes are for instance implicated in the reduction of oxygen, nitrite, sulfite, and the reductive activation of oxygen, among others. ${ }^{[4]}$ Although metalloporphyrins are not involved at the catalytic sites of the key enzymes that fix $\mathrm{CO}_{2}$ in nature, ${ }^{[8]}$ chemists have been interested in examining their potentialities for this particular task.

Early papers from the 1970's were reported on the electrocatalytic activity of metalloporphyrins toward $\mathrm{CO}_{2}$ reduction. ${ }^{[9]}$ Importantly though, Savéant and coworkers were the first to provide a profound electrochemical investigation on the two-electron reduction of $\mathrm{CO}_{2}$ to $\mathrm{CO}$ with the iron (III) tetraphenyl porphyrin (FeTPP, catalyst 1 in Figure 1). ${ }^{[0]}$ In a general proposed mechanism, the catalyst undergoes three reversible reductions attributed to the formal redox couples $\mathrm{Fe}^{\text {III/II }}$, $\mathrm{Fe}^{\mathrm{Il} / 1}$, and $\mathrm{Fe}^{1 / 0}$ (Figure 1a). The active $\mathrm{Fe}^{0}$ species is nucleophilic enough to react with the $\mathrm{CO}_{2}$ substrate forming a $\left[\mathrm{Fe}-\mathrm{CO}_{2}\right]$ intermediate. This is followed by a concerted process of protonation and intramolecular electron transfer, breaking one of the $\mathrm{C}-\mathrm{O}$ bonds to form an $\mathrm{Fe}^{11}-\mathrm{CO}$ adduct (Figure 1c). ${ }^{[11]}$ Seminal works highlighted the importance of Lewis acids (e.g. $\left.\mathrm{Mg}^{2+}\right)^{[12]}$ and Brønsted acids (e.g. acetic acid, phenol, trifluoroethanol, water ${ }^{[13,14]}$ in modulating the electrocatalytic activity (Figure 1d), possibly by intervening through intermediate proton-coupled steps. $\mathrm{CO}$ is then released after homogeneous one-electron reduction by another $\mathrm{Fe}^{0}$ species, closing the catalytic cycle. Beyond mechanistic analysis, Savéant has crucially established a stage for rational benchmarking of $\mathrm{CO}_{2}$ reduction performance ${ }^{[15-18]}$ that ultimately guided rational design principles ${ }^{[19]}$ to control and improve the intrinsic electrocatalytic activities of metalloporphyrins. Herein, we will focus on the chemical parameters that are at hand of chemists to shift the electrocatalytic characteristics of this family of complexes into a domain where technological implementation can be anticipated. The objective of this paper is not to provide an extensive review $^{[20-25]}$ but rather to put in perspective our own efforts and those of others in manipulating the electrochemical properties of metalloporphyrins for $\mathrm{CO}_{2}$ reduction. 

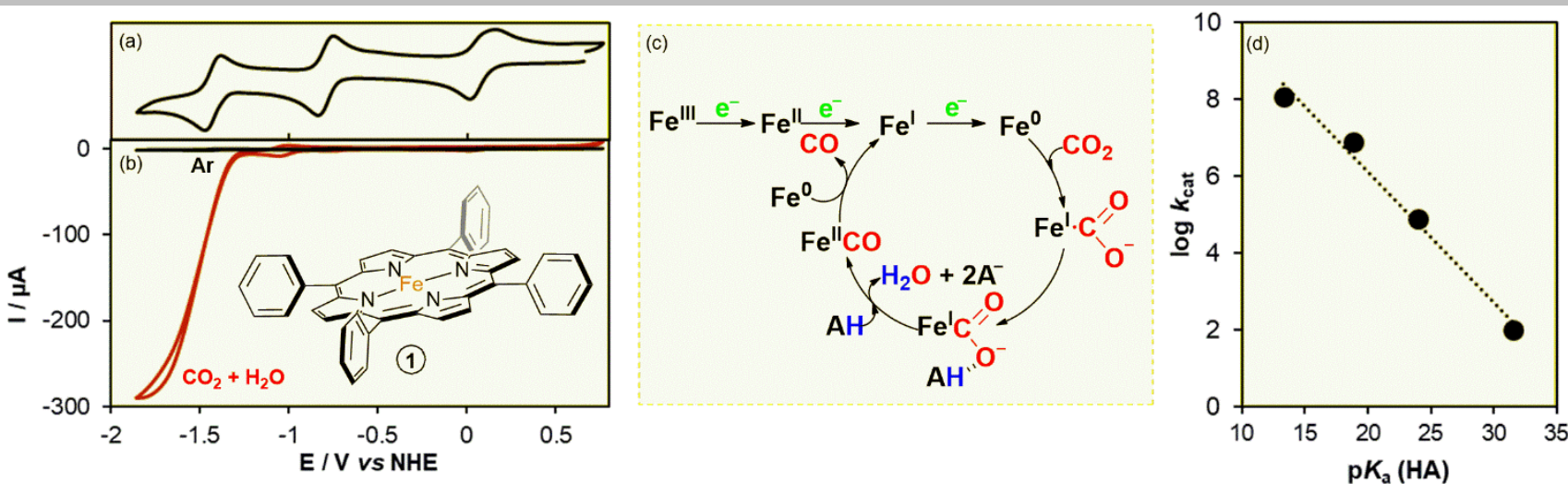

Figure 1. (a) Cyclic voltammogram (CV) of iron tetraphenylporphyrin (FeTPP, 1) in dimethylformamide under argon atmosphere and (b) upon saturation with $\mathrm{CO}_{2}$ and addition of $5.5 \mathrm{M} \mathrm{H}_{2} \mathrm{O}$. (c) Savéant's simplified proposed catalytic mechanism based on CV and isotopic studies. (d) Importance of pK $K_{\mathrm{a}}$ of exogenous proton source (acetic acid, phenol, trifluoroethanol, water) in modulating the global catalytic rate constant. (Data taken from Ref. ${ }^{[11]}$ )

\section{Figures of Merit}

Homogenous molecular electrocatalysts for $\mathrm{CO}_{2}$ reduction are evaluated based on their catalytic activity, energetic efficiency, selectivity, and stability. The activity of the catalyst is reported by the rate of the catalytic reaction in the form of turnover frequency (TOF). The higher the TOF, the more products are formed per catalyst per unit of time $\left(\mathrm{s}^{-1}\right)$. The energetic efficiency refers to how efficiently electrical energy is utilized to perform the reaction and it is described in terms of Faraday efficiency and overpotential. Faraday efficiency is determined by dividing the equivalent amount of electrons stored in the products formed by the total amount of charge passed during preparative-scale electrolysis. Since it includes product distribution, Faraday efficiency is also often used to define the selectivity of the system. Overpotential $(\eta)$ refers to the additional potential needed to be applied to the system past the thermodynamic potential of the reaction. The high Faraday efficiency of iron porphyrins towards selective $\mathrm{CO}_{2}$-to- $\mathrm{CO}$ production and their good stability, ${ }^{[26-34]}$ have left most of the design improvements focused on increasing TOF and lowering overpotential.

Philipp Gotico, from the Philippines, received his $\mathrm{PhD}$ in Chemistry at the French Alternative Energies and Atomic Energy Commission (CEA) focused on molecular catalyst design and characterization. After a postdoctoral stint at the Institute of Molecular Sciences of Orsay (France) on time-resolved spectroscopies, he is now working at Helmholtz-Zentrum Berlin (Germany) on hybrid interfaces for photoelectrochemical conversion of carbon dioxide.

Zakaria Halime, from Morocco, received his $\mathrm{PhD}$ in Chemistry from the University of Rennes 1, France. After a postdoctoral experience in Kenneth D. Karlin's group at Johns Hopkins University, USA, and then Shunichi Fukuzumi's group at Osaka University, Japan. he was appointed in 2016 a Senior Researcher position at CNRS and University Paris Saclay where he is currently working on the catalytic transformation of small molecules into sustainable fuels.
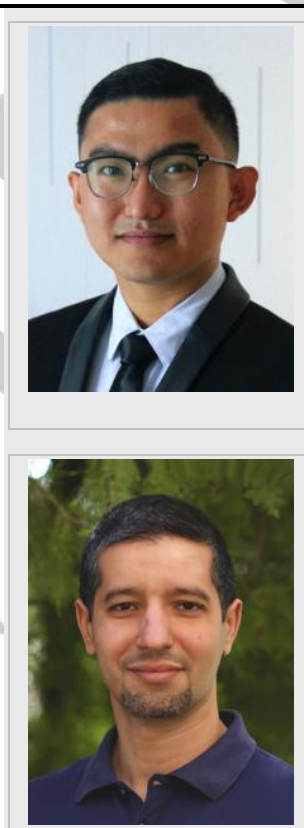

Systematic investigation of catalytic systems using TOF and overpotential is a challenging task requiring preparativescale electrolysis which are often influenced not only by intrinsic catalytic activities but also by contingent effects of electrochemical cell geometry, ohmic drops, and transport parameters. Savéant and colleagues have pioneered a rational non-destructive tool for quick estimation of the TOF, called the foot-of-the-wave analysis (FOWA) of the standard cyclic voltammetry (CV) measurements. ${ }^{[15]}$ This analysis takes into account the catalytic reaction rate happening within the electrode's reaction-diffusion layer, preventing any contributions from side phenomena such as substrate consumption, catalyst deactivation and/or product inhibition.
Winfried Leibl, from Germany, obtained his PhD from the University of Osnabrück, Germany. He joined the biophysics group at CEA Saclay (France) with a postdoctoral fellowship to work on primary events in natural photosynthesis before being appointed a Senior Researcher position at the same Institute. He is currently heading a group focused on functional characterization of bio-inspired photocatalytic systems.

Ally Aukauloo, from Mauritius, obtained his $\mathrm{PhD}$ in a joint venture of Profs. R. Guilard, E. Vogel and K. Kadish on porphyrin isomers. He started as an associate professor in the field of molecular magnetism. In 2000, after a stay in Prof. J. Collman lab at Stanford University working on Cytochrome c Oxidase models, he shifted to bioinorganic chemistry focussing on Artificial Photosynthesis. He is currently full professor at Universié Paris Saclay and research collaborator at the CEA-Saclay.

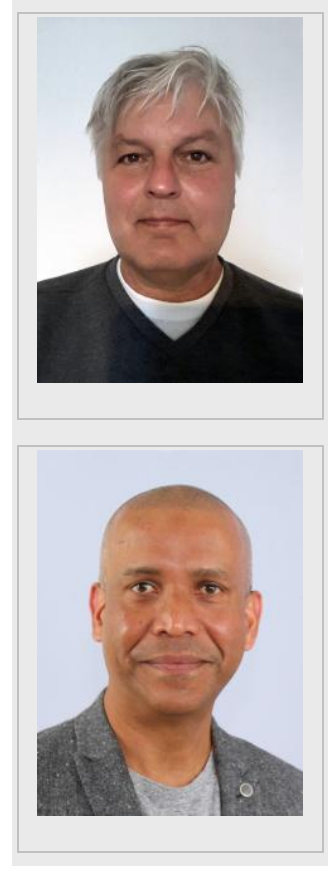


Mathematical derivation, assumptions, and mechanistic variations are detailed elsewhere, ${ }^{[16-18]}$ and here we give a gist for non-specialists. From the CV measurements in the absence and presence of $\mathrm{CO}_{2}$ substrate, the analysis proceeds with the linear correlation between the current ratio $\left(i / i_{p}{ }^{0}\right)$ and the potential-dependent term $1 /\left\{1+\exp \left[(F / R T)\left(E-E_{\text {cat }}^{0}\right]\right\}\right.$, where $i$ is the catalytic current in the presence of $\mathrm{CO}_{2}, i_{p}^{0}$ is the peak current in the absence of $\mathrm{CO}_{2}, F$ is the Faraday constant, $R$ is the gas constant, $T$ is the absolute temperature, $E$ is the applied potential, and $E_{\text {cat }}^{0}$ is the standard potential of the reversible reduction peak of the catalyst's active form (i.e. $\mathrm{Fe}^{1 / 0}$ couple for iron porphyrins):

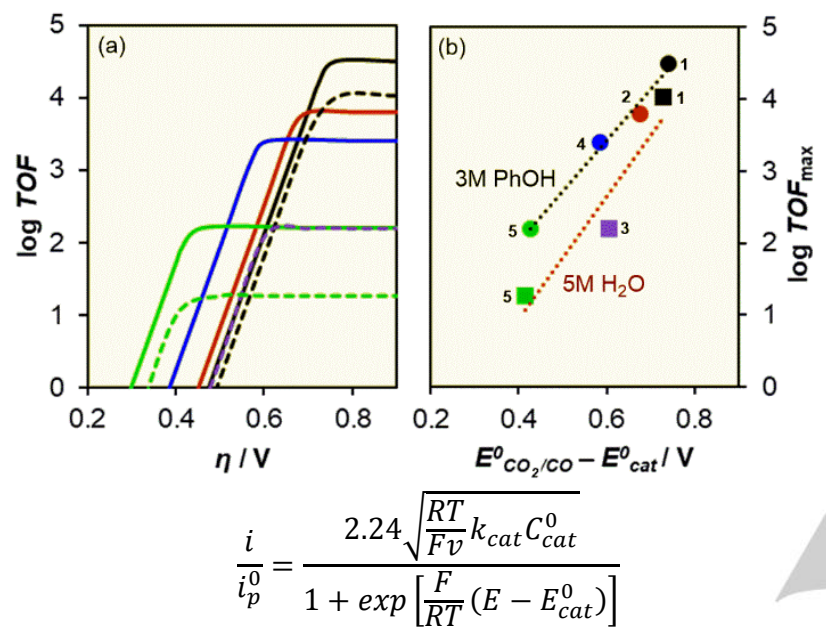

Tracing these two terms $1 /\left\{1+\exp \left[(F / R T)\left(E-E_{\text {cat }}^{0}\right)\right]\right\}$ vs $i / i_{p}^{0}$ in the foot-of-the-wave region of the $C V$ produces a straight line with a slope $=2.24(R T / F v)^{0.5}\left(k_{\text {cat }} C_{\text {cat }}^{0}\right)^{0.5}$ where $v$ is the scan rate in $\mathrm{Vs}^{-1}$ and $C^{0}{ }_{\text {cat }}$ is the initial concentration of the $\mathrm{CO}_{2}$ substrate. The catalytic rate constant, $k_{\text {cat }}$, can then be computed from this slope.

Plotting the kinetic term of TOF and the thermodynamic quantity of overpotential, i.e., $\eta=E_{\mathrm{CO}_{2} / \mathrm{CO}}^{-} E$, where $E_{\mathrm{CO}_{2} / \mathrm{CO}}^{0}$ is the thermodynamic potential for the $\mathrm{CO}_{2}$ reduction process involved and $E$ is the applied potential, a catalytic Tafel plot is generated, as shown in Figure 2a:

$$
T O F=\frac{k_{c a t} C_{c a t}^{0}}{1+\exp \left[\frac{F}{R T}\left(E_{c a t}^{0}-E_{\mathrm{CO}_{2} / \mathrm{CO}}^{0}-\eta\right)\right]}
$$

Gathering the catalytic Tafel plots for each catalyst in the same diagram then becomes a benchmarking tool comparing intrinsic catalytic activities and optimal operating conditions. With the objective of improving the catalytic rate (higher TOF) and lowering the overpotential, a good catalyst would be envisioned to have a catalytic Tafel plot shifted diagonally to the upper left (Figure 2b).

\section{Controlling the Electronic Parameters}

From the two figures of merit discussed above, lowering the overpotential of the catalytic $\mathrm{CO}_{2}$ reduction is still a major concern. This is a desirable objective from an energetic efficiency point of view especially when the $\mathrm{CO}_{2}$ reduction halfreaction is coupled to the energy-demanding 4-electron 4-proton
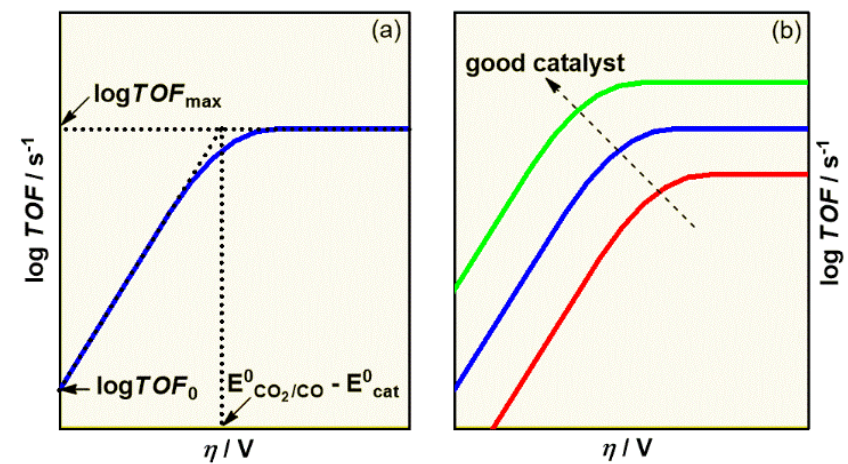

water oxidation half-reaction but also with respect to the inclusion of such molecular catalysts in photocatalytic and
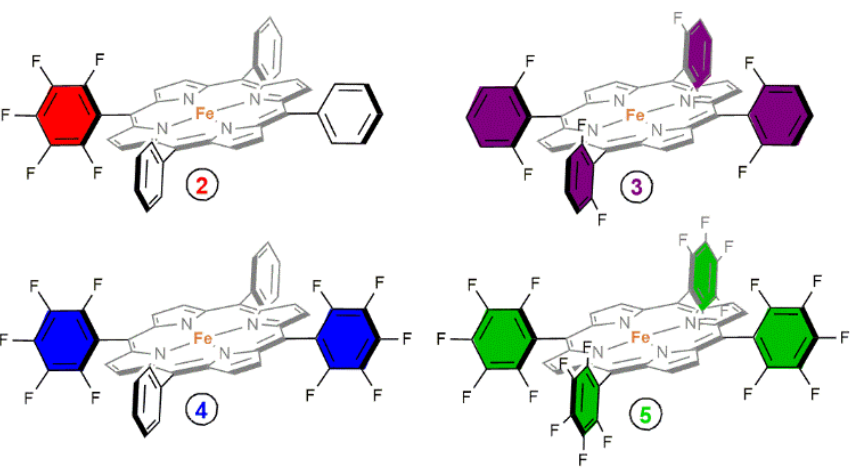

photoelectrochemical processes. This is particularly challenging as multiple electron transfers are involved to prepare the catalyst in the active form and furthermore to perform multi-electron and proton reactions during the catalytic cycle.

Figure 2. (a) Catalytic Tafel plot relating turnover frequency (TOF) and overpotential $(\eta)$ as catalytic performance parameters derived from CV-based foot-of-the-wave analysis (see discussion). (b) Expected shift of the catalytic Tafel plot (from red to green) when improving the catalytic performances of a scatalyst.

A classical strategy of lowering the overpotential of the catalytic system is through the incorporation of functional groups that can induce through-structure electronic effects. A typical example includes the introduction of electron-withdrawing groups such as fluorine atoms on the phenyl groups on the porphyrin framework. This facilitates electron injection into the molecular catalysts, shifting the redox potentials of the formal $\mathrm{Fe}^{1 / 0}$ couple where catalysis occurs, to more positive values. The end effect is a direct shift to lower overpotential of the catalytic reaction. These electronic effects are cumulative in a way that increasing the number of fluorine atoms from five to eight to ten and to twenty in catalysts $2,3,4$, and $\mathbf{5}$, respectively results in systematic lowering of the overpotential of the catalytic reaction (Figure 3). ${ }^{[29-31,33]}$ This is manifested as a leftward shift in the catalytic Tafel plot in Figure 3a. However, this strategy comes at the price of lower TOF, manifested as a downward shift along the log TOF axis of the catalytic Tafel plot. In fact, shifting anodically the reduction potential at which the $\mathrm{Fe}^{0}$ active species is generated, renders this species less nucleophilic and less prompt to activate the $\mathrm{CO}_{2}$ substrate. Further analysis of this global inductive effect has pinpointed the influence of such functionalities not only on the Lewis basicity of the $\mathrm{Fe}^{0}$ but also on the Bronsted basicity of the oxygens in the iron- $\mathrm{CO}_{2}$ 
adduct. $^{[29]}$ This highlights the critical electronic push-pull

framework at play during $\mathrm{CO}_{2}$ reduction.

Figure 3. (a) Catalytic Tafel plots of iron porphyrins employing different numbers of fluorine atoms as electron-withdrawing groups (structures shown on the right) and (b) corresponding correlation of $\mathrm{TOF}_{\max }$ with the catalytic potential $E_{\text {cat }}^{0}$ showing through-structure electronic effects. Condition: $\mathrm{CO}_{2}$-saturated $\mathrm{DMF}$ with two different proton sources: $3 \mathrm{M}$ phenol (circles) or $5.5 \mathrm{M} \mathrm{H}_{2} \mathrm{O}$ (squares).

The overlapping catalytic Tafel plots of the catalysts in Figure $3 \mathrm{a}$, though providing useful information for optimal operating conditions, often become hard to read when comparing even more catalysts. One simple systematic analysis is shown in Figure $3 \mathrm{~b}$ by plotting the $\log \left(T O F_{\text {max }}\right)$ vs the overpotential related to the catalytic redox couple $\left(\eta^{\prime}=E_{\mathrm{CO}_{2} / \mathrm{CO}-}^{-}\right.$ $E_{\text {cat }}^{0}$ ). This data is simply the intersection between the two asymptotes of the Tafel plot as pinpointed in Figure $2 \mathrm{a}$ and contains relevant performance indices for the catalytic reaction. A Hammett-type linear free energy relationship exists within this through-structure electronic correlation line, similar to correlating the catalytic rate with the standard potential of the $\mathrm{Fe}^{1 / 0}$ redox couple as shown by Savéant. ${ }^{[19]}$ From the read of Figure 3b, it becomes clear that, while the effect of the electron withdrawing groups lowers the overpotential of the catalytic reaction it also pulls down the reaction rate, a contradictory effect in quest for merging lower overpotential with higher catalytic rate. As observed, slight drops in the overpotential cause large declines in the $T O F_{\max }$, thereby rendering this particular strategy in the $\mathrm{CO}_{2}$ reduction not a valuable route. ${ }^{[29]}$

\section{Going Beyond Electronic Effects}

The challenge of veering away from the linear correlation dilemma between the catalytic rate and the dictated overpotential, brought by the intrinsic limitations of throughstructure inductive electronic effects, led chemists to design more elaborate systems going beyond the primary coordination sphere of the catalysts' metal active site. Such inspiration comes from similar substrate activation found in enzymes, in particular the $\mathrm{CO}$ dehydrogenase (CODH) enzymes, where amino acid residues located in the close surrounding of the metal active sites also steer the structure-reactivity pattern towards the $\mathrm{CO}_{2}$ substrate. Set apart the enforced geometry at the metal sites, hydrogen bonding network and proton delivery schemes entertain a minimal reorganizational energy and overpotential landscape. ${ }^{[35]}$ These chemical facets have been deployed in the second coordination sphere of molecular catalysts acting as through-space players, in the activation of the $\left[\mathrm{Fe}-\mathrm{CO}_{2}\right]$ adduct and the proceeding proton-coupled intermediates. These effects are generally classified as local proton sources, hydrogen bond relays and electrostatic interactions and alternatively may include additional through-structure electronic effects.

\subsection{Hydrogen Bond Relays}

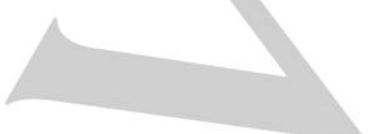

Seminal works of Bhugun and Savéant have stressed the importance of exogenous Brønsted acids ${ }^{[13,14]}$ in critically modulating the electrocatalytic $\mathrm{CO}_{2}$ reduction activity of iron porphyrins (Figure 1d), pointing to the rate-limiting protoncoupled steps in the catalytic cycle (Figure 1c). This led to one of the early examples of a successfully tailored iron porphyrin with pendent phenol groups (catalyst 6, Figure 5) achieving high $\log T_{O} F_{\max }$ of 5.97 at $\eta^{\prime}=0.64 \mathrm{~V}$ in DMF with $2 \mathrm{M} \mathrm{H}_{2} \mathrm{O}$ (Figure 4). ${ }^{[26]}$ These functionalities act both as hydrogen bond donors activating the $\mathrm{CO}_{2}$ substrate and, because of their low $\mathrm{p} K \mathrm{a}$, act also as a local proton source. Methylating the hydroxyl groups to methoxy ones results in a fall in the activity $\left(\log T O F_{\max }=2.7\right)$ at a much higher overpotential $\left(\eta^{\prime}=1.00 \mathrm{~V}\right)$. These results clearly emphasize the specific role as local proton source played by the pendent phenols in the close proximity of the metal center. ${ }^{[27]}$ Combining both the inductive electronic effects of fluorine atoms and the local proton source in catalyst 7 accordingly resulted in a lowering of the overpotential $\left(\eta^{\prime}=0.59 \mathrm{~V}\right)$ but unfortunately the adverse electronic effect of the fluorine groups again prevails leading to a decrease in the activity $\left(\log T O F_{\max }=4.0\right)$ of the catalyst. The choice of the exogenous proton source seems to critically influence the activities of such functions. Using $3 \mathrm{M}$ $\mathrm{PhOH}$ (circular markers in Figure 4) instead of $\mathrm{H}_{2} \mathrm{O}$ as proton source in DMF, the same catalyst 6 does not show significant improvements $\left(\log T O F_{\max }=3.8, \eta^{\prime}=0.66 \mathrm{~V}\right)$ compared to the nonfunctionalized catalyst $1\left(\log T O F_{\max }=4.5, \eta^{\prime}=0.74 \mathrm{~V}\right)$, indicating that these pendent phenol groups compete with the bulk exogenous proton source in activating the metal carboxylate intermediate. ${ }^{[27]}$ However, using a proton source with a much higher $p K_{\mathrm{a}}$, such as water, allows catalyst 6 to display a more confined acidic environment which enhances the proton-coupled breaking of the C-O bond. The importance of proper distancing of such phenol groups from the metal carboxylate adduct becomes critical as exemplified in an iron hangman porphyrin bearing a pendent phenol attached to a dibenzofuran cleft in catalyst $\mathbf{8}$. The group of Nocera showed a lower catalytic activity for their proposed model 8 even though the distant phenol was inducing an initial $-5.0 \mathrm{kcal} / \mathrm{mol}$ stabilization of the $\mathrm{CO}_{2}$ adduct. ${ }^{[36]}$ Swopping the pendent hydroxyl groups in this hangman porphyrin to sulfonic acid resulted in an even lower activity. This is due to the fact that once this group is deprotonated, they cannot be reprotonated by the weaker exogenous $\mathrm{PhOH}$ proton source ( $\mathrm{p} K_{\mathrm{a}}$ of sulfonic acid $=3<\mathrm{p} K_{\mathrm{a}}$ of $\mathrm{PhOH}=18$ in $\left.\mathrm{DMF}^{[37]}\right)$. The net effect results in an electrostatic repulsion where the negatively charged sulfonic group is no longer directed towards the bound $\mathrm{CO}_{2}$ substrate. ${ }^{[36]}$ This study underlines the importance of exogenous proton sources in regenerating the intended function of such local proton sources. 


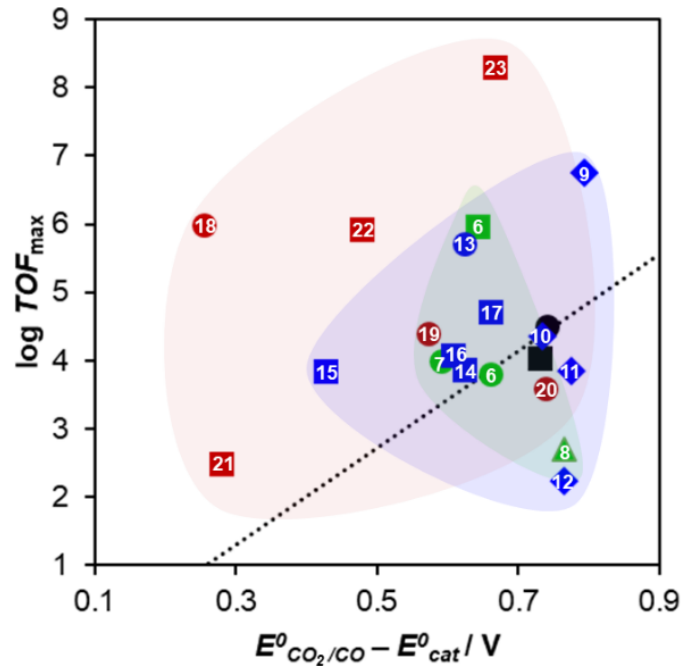

Figure 4. Comparison of the catalytic performance of modified iron porphyrins having functional groups acting as local proton source (green), hydrogen bond relays (blue), and electrostatic interactions (red) compared to the nonfunctionalized complex 1 (black). Numbers correspond to structures in Figure 5 and markers with the following conditions: $\mathrm{CO}_{2}$-saturated DMF with $3 \mathrm{M}$ phenol (circle), $0.04 \mathrm{M} \mathrm{PhOH}$ (triangle), $0.1 \mathrm{M} \mathrm{PhOH}$ (diamond), or $5.5 \mathrm{M} \mathrm{H}_{2} \mathrm{O}$ (square); Cat 13 in ACN with $3 \mathrm{M} \mathrm{PhOH}$. Performance of nonfunctionalized catalyst 1 shown in black and through-structure electronic correlation shown as dotted lines for comparison.

The above-mentioned observations have led to further optimization focusing on sole hydrogen bond donors that are able to establish hydrogen bonding interactions with the metal carboxylate adduct and/or with the exogenous proton sources to synergistically activate $\mathrm{CO}_{2}$ reduction intermediates. The group of Chang has reported important design considerations when systematically installing pendent amide groups in a hangman porphyrin configuration. They found that the positioning of the amide group in ortho position in the meso aryl of the porphyrin (catalysts 9 and 11 with $\log T O F_{\max }=4.35$ to 6.74 ) outperforms their analogues with a para configuration (catalysts $\mathbf{1 0}$ and $\mathbf{1 2}$ with $\log T O F_{\max }=2.23$ to 3.84$)$ at similar overpotentials $\left(\eta^{\prime}=\right.$ 0.74 to $0.80 \mathrm{~V}$ ). Such a change was accordingly attributed to the position and the orientation of the $\mathrm{N}-\mathrm{H}$ fragments that are more optimal for hydrogen bond interactions with the $\mathrm{CO}_{2}$ adduct in the ortho than in the para positioning. More subtly, introducing a flexible $-\mathrm{CH}_{2}$ - spacer on the phenyl ring to hold the $\mathrm{N}-\mathrm{H}$ amido fragment in catalyst $\mathbf{9}$ yields better catalytic activities compared to the direct linkage to the meso aryl in catalyst 11. Here too, it can be appreciated how molecular engineering can direct the reactivity of the porphyrin catalyst. In the present case the flexibility of the amido function may adapt to establish a stronger interaction with the activated $\mathrm{CO}_{2}$ substrate. Of note, the positioning and accessibility of the $\mathrm{N}-\mathrm{H}$ amido group to engage in hydrogen bonding interaction is also important. This is clearly evidenced in comparing the activity of $\mathbf{1 1}$ with $\mathbf{1 0}$. Even though in $\mathbf{1 1}$ the amide group is in the ortho position of the phenyl ring its performance is found to be inferior to the one of catalyst $\mathbf{1 0}$ that has a distal $\mathrm{N}-\mathrm{H}$ fragment in the para position. The flexible bulky group on the rigid amide group in the ortho position may actually prevent any set up of a hydrogen bonding interaction. Structural modelization or crystal structures may provide insights on this issue. Nevertheless, these catalysts improved the TOF of the nonfunctionalized parent catalyst $\mathbf{1}$ under the same electrochemical conditions (DMF with $0.1 \mathrm{M} \mathrm{PhOH}$ ), however with only a minimal effect on the overpotential.

Important lowering of the overpotentials were achieved when employing four proximal amide groups in an aaaa atropisomer configuration in catalyst $\mathbf{1 3}$ by the group of Dey achieving a $\log T O F_{\max }=5.71$ at $\eta^{\prime}=0.62 \mathrm{~V}$ in ACN with $3 \mathrm{M}$ $\mathrm{PhOH}^{\left[{ }^{[38]}\right.}$ This result suggests that, in addition to their hydrogen bond donor role, the amide groups display as well cumulative inductive effects, given that the $\mathrm{Fe}^{1 / 0}$ redox couple is anodically shifted even in the absence of the $\mathrm{CO}_{2}$ substrate. ${ }^{[39,40]}$ An atropisomer having the same number of proximal amides but in 


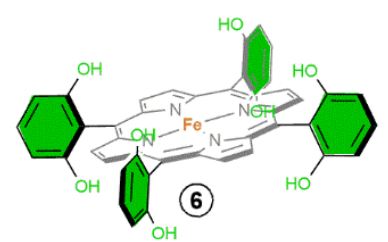<smiles>O=C(Nc1cc(C(F)(F)F)cc(C(F)(F)F)c1)C1C2CCC(O2)C1C(F)(F)F</smiles>

$\mathrm{CF}^{\mathrm{CF}}$
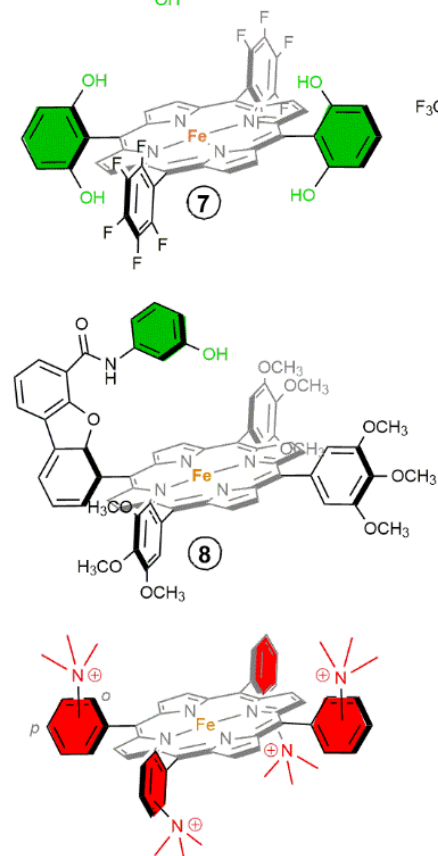

(18) o-anilinium (isomeric mix) (19) $p$-anilinium

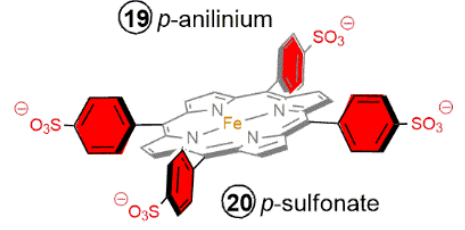

(20) p-sulfonate
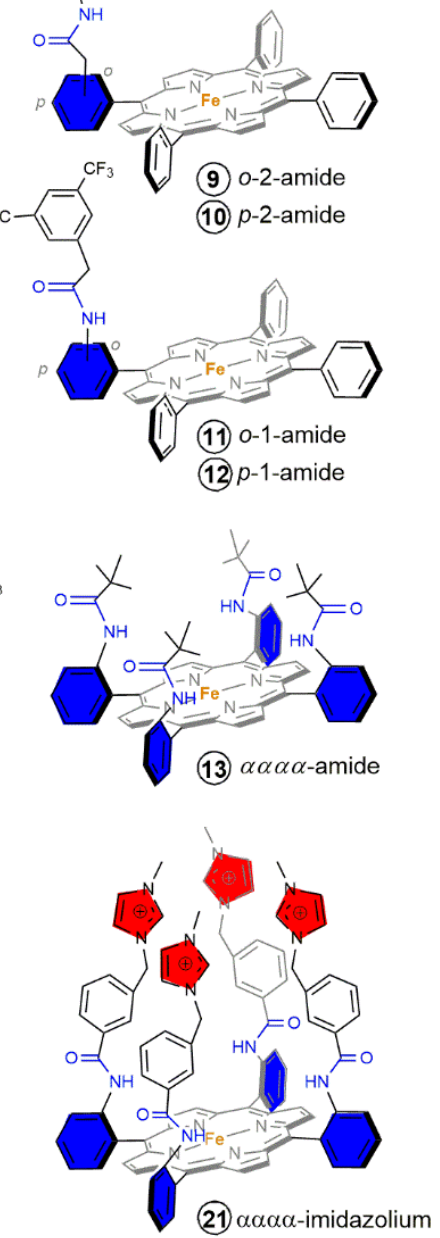

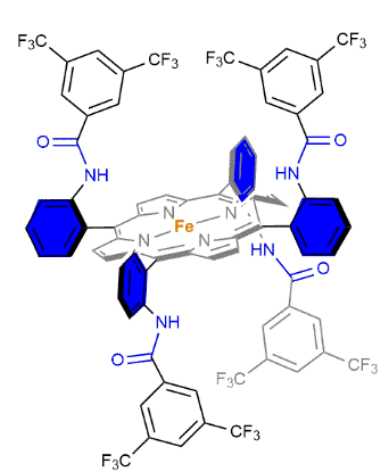

(14) $\alpha \beta \alpha \beta$-amide

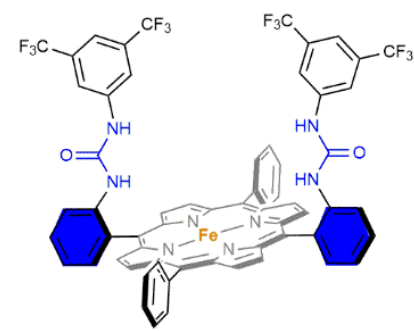

(16) $\alpha \alpha$-urea

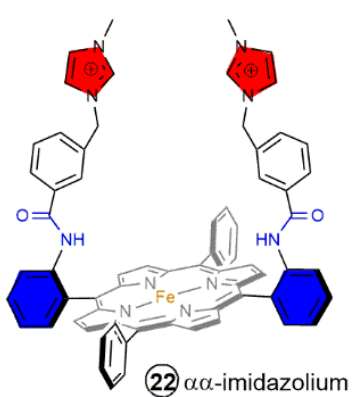

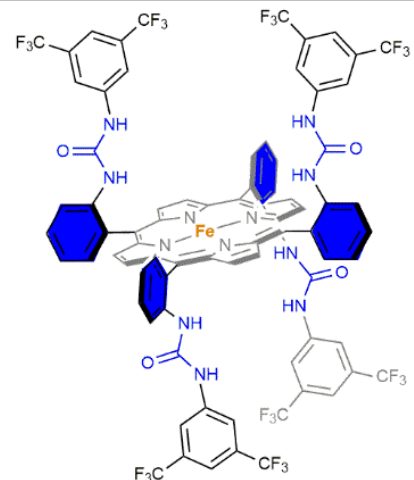

(15) $\alpha \beta \alpha \beta$-urea

Figure 5. Diversity of modified iron porphyrins with functional groups acting as local proton source (green), hydrogen bond relays (blue), and electrostatic interaction sources (red) in various topological configurations.

$\alpha \beta \alpha \beta$ configuration in catalyst $\mathbf{1 4}$ synthesized by our group shows similar overpotential but operates at much lower log TOF $_{\text {max }}$ of 3.85 in DMF with $5.5 \mathrm{M} \mathrm{H}_{2} \mathrm{O}^{[31]}$ This is possibly because four amide arms can be involved in the hydrogen bonding network interacting with the $\left[\mathrm{Fe}-\mathrm{CO}_{2}\right]$ adduct in catalyst 13 whereas in catalyst $\mathbf{1 4}$ only two amide arms on each side of the molecular plane can participate in this network. However, the differences in the catalytic conditions used for the two catalysts (tert-butyl vs fluorinated-phenyl as tailing groups, ACN vs DMF as solvent, and $\mathrm{PhOH}$ vs $\mathrm{H}_{2} \mathrm{O}$ as proton source) demand for further systematic analysis.

Pushing further the optimization of hydrogen bond relays in the second coordination sphere, our group has systematically compared the single-point hydrogen bonding induced by the amides of catalyst $\mathbf{1 4}$ with the multi-point hydrogen bonding induced by the urea groups of catalyst $15 .^{[31]}$ The idea of using urea groups comes from independent studies where a urea scaffold was shown to capture atmospheric $\mathrm{CO}_{2}$ as carbonate clusters held together by a multi-point hydrogen bonding network $^{[41]}$. The use of exogenous urea groups had also been demonstrated to improve the TOF of nickel cyclams at the same overpotential. ${ }^{[42]}$ Indeed, the introduction of urea groups in the second coordination sphere of catalyst $\mathbf{1 5}$ significantly lowered the overpotential of the catalytic reaction attaining $\eta^{\prime}=0.43 \mathrm{~V}$ while maintaining a good log TOF $\max$ of 3.83 similar to the TOFs of catalyst 14 and the nonfunctionalized catalyst 1 in DMF with $5.5 \mathrm{M} \mathrm{H}_{2} \mathrm{O}$. This significant enhancement in the catalysis was attributed to an improved $\mathrm{CO}_{2}$ binding assisted by the urea arms as evidenced by short hydrogen bonding $(\mathrm{N})-\mathrm{H} \cdots \mathrm{O}(\mathrm{C})$ distances of $1.76-1.88 \AA$ compared to those provided by amide groups in catalyst 14 (2.01 - 2.35 ̊). Similar hydrogen bonding schemes are found in the active site of $\mathrm{CODH}$ enzymes and are suggested to participate actively in the $\mathrm{CO}_{2}$ activation.

The initial intent of having the $\alpha \beta \alpha \beta$ configuration in catalyst $\mathbf{1 5}$ was to mimic the fashion in which lysine and histidine residues interact independently with each oxygen atom of the metal carboxylate intermediate in $\mathrm{CODH}$. We further interrogated the dissymmetric functional features of these nearby amino acid residues by comparing the $\alpha \alpha$ and $\alpha \beta$ atropisomers in catalysts 16 and 17, respectively. This subtle topological change induced a higher log $T O F_{\max }$ of 4.71 and overpotential $\left(\eta^{\prime}=0.66\right)$ for the $\alpha \beta$ atropisomer compared to the $\alpha \alpha$ analogue. ${ }^{[32]}$ While the $\alpha \alpha$ atropisomer exhibited higher $\mathrm{CO}_{2}$ binding aptitude compared to the $\alpha \beta$ analogue, the former exhibited high values of kinetic isotope effect (7.60) when using $\mathrm{H}_{2} \mathrm{O} / \mathrm{D}_{2} \mathrm{O}$ as proton source in $\mathrm{DMF}$, implicating that proton transfer is involved in the rate-determining step and suggesting the eventual presence of a tight hydrogen bonding network. On 
the other hand, the higher catalytic rate observed with the $\alpha \beta$ atropisomer and lower values of KIE (1.04) concurs to an optimized locking of the $\mathrm{CO}_{2}$ substrate with one urea pillar, while the 'loose' oxygen atom of the metal bound $\mathrm{CO}_{2}$ is sterically-free for the convoy of protons from the exogenous proton source.

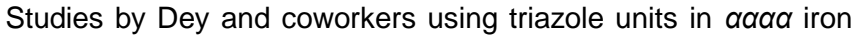
porphyrin catalysts to trap water molecules which indirectly activate the $\mathrm{CO}_{2}$ adduct, showed slight effects on overpotential $\left(\eta^{\prime}=0.50\right.$ to $\left.0.54 \mathrm{~V}\right)$ and catalytic activity $\left(\log T O F_{\max }=2.4\right.$ to 3.0). ${ }^{[38]}$ The group of Jiang has also investigated on atropisomeric effects in zinc porphyrin decorated with triazole units. However, the observed effects on the TOF were found to be small indicating a key role of the iron redox properties in the catalytic cycle. ${ }^{[43]}$ The incorporation of eight triazole units via flexible oxymethylene linkers in iron porphyrins led to increased $\log T O F_{\max }$ of 4.74 albeit at higher overpotential of $0.78 \mathrm{~V}^{[44]}$ Hydrophilic polyethylene glycol chains acting as proton shuttling relays in the surrounding of the coordination sphere of zinc porphyrins were also found to influence to some extent the catalytic pattern $\left(\log T O F_{\max }=3.26, \eta^{\prime}=0.98 \mathrm{~V}\right) .{ }^{[45]}$ These studies reveal that, even though there is an incentive to incorporate functional groups that can help capture and activate the $\mathrm{CO}_{2}$ substrate, it is important as well to consider the management of the proton supply towards the activated metal carboxylate adduct.

\subsection{Electrostatic Interactions}

The group of Savéant has driven the catalytic performance of iron porphyrins in electrocatalytic $\mathrm{CO}_{2}$ reduction even further by introducing an unprecedented catalyst 18 (isomeric mix of $\alpha \beta \alpha \beta$, $\alpha \alpha \beta \beta$, $\alpha \alpha \alpha \beta$, and $\alpha \alpha \alpha \alpha)$ with a second coordination sphere displaying a through-space electrostatic effect. The presence of these cationic motifs also serves to bring solubility in an aqueous medium. The incorporation of trimethylammonium groups in the ortho position of the aryl groups in catalyst 18 significantly decreased the overpotential $\left(\eta^{\prime}=0.25 \mathrm{~V}\right)$ while simultaneously increasing the catalytic rate $\left(\log T O F_{\max }=6\right) .{ }^{[30]}$ This catalyst exhibited $100 \%$ Faraday efficiency for CO production over $84 \mathrm{~h}$ electrocatalysis in DMF with $3 \mathrm{M} \mathrm{PhOH}$ and $0.1 \mathrm{M} \mathrm{H}_{2} \mathrm{O}$. The proper positioning of these cationic groups is important again here as placing them in the para positions of the meso aryl groups in catalyst 19 resulted in higher overpotential $\left(\eta^{\prime}=0.57 \mathrm{~V}\right)$ and lower catalytic activity (log $\left.T O F_{\max }=4.4\right) .{ }^{[28,30]}$ Control experiments, where negativelycharged sulfonates were incorporated in catalyst 20 , show severe decrease in the $\log T O F_{\max }$ (3.6) and increase of the overpotential $\left(\eta^{\prime}=0.74 \mathrm{~V}\right)$ due to the electrostatic repulsions between the sulfonate groups and the negatively-charged metal carboxylate intermediate. ${ }^{[30]}$ This downgraded performance was similarly observed for sulfonates and carboxylates in hangman iron-porphyrins. ${ }^{[36,46]}$

Masel and coworkers reported on a massive drop in overpotential for the $\mathrm{CO}_{2}$ reduction to $\mathrm{CO}$ from $1 \mathrm{~V}$ to $0.17 \mathrm{~V}$ at a silver electrode when performing electrocatalysis in presence of imidazolium-based ionic liquid. ${ }^{[4]}$ The main explanation for this observation was that the imidazolium units served in the stabilization of the $\mathrm{CO}_{2}{ }^{-}$species. Based on these findings, we developed a picket fence-type catalyst $\mathbf{2 1}$ combining the through-space electrostatic effect of methylimidazolium groups as ionic liquid component and with an added hydrogen bonding effect from the proximal amido groups, resulting in an interestingly lower overpotential $\left(\eta^{\prime}=0.37 \mathrm{~V}\right)$. Lessons from biology are constantly helping chemists to implement chemical subtleties that can help to boost the catalytic activities of bioinspired models. Along this line, A. Warshel has decisively demonstrated that electrostatic effects were responsible for the unmatched catalytic power of enzymes. ${ }^{[48-50]}$ With the mindset to interrogate this facet in model complexes, we later varied the number of these cationic groups in catalysts $\mathbf{2 1}, \mathbf{2 2}$, and $\mathbf{2 3}$ from four, to two, and to one, respectively, and found that the catalytic overpotential is a function of the number of embarked imidazolium groups (ranging from 230 to 430 to $620 \mathrm{mV}$ from tetra- to mono-substituted porphyrin respectively). ${ }^{[34]}$ This revealed the cumulative nature of through-space electrostatic effects, as previously observed for through-bond inductive effects of the fluorine atoms or the cumulative effect of hydrogen bond relays. More importantly, the slope of the TOF vs catalytic potential becomes much steeper in the case of electrostatic interactions achieving the highest reported log $T O F_{\max }$ of 8.31 for the mono-substituted catalyst 23, albeit at higher overpotentials. A thorough theoretical analysis together with more models are still needed to unravel how these cationic groups affect each step of the catalytic cycle. However, they stand to date as the most significant player in optimizing the electrocatalytic performance of iron porphyrins for the reduction of $\mathrm{CO}_{2}$ to $\mathrm{CO}$, as depicted in Figure 4.

\section{Implications to other Catalytic Systems}

Strategies employing second coordination sphere effects have also been transposed in other catalytic systems, though activity benchmarking was not as evident and extensive as that of the iron porphyrin system. The foot-of-the-wave analysis to estimate catalytic rate constants finds its limited use in these systems, especially the Re and Mn bpy-based catalysts, ${ }^{[51-53]}$ as multimodal catalytic waves deviate from the ideal behavior, indicating that the simplified EC mechanism may not apply. In addition, the difficulty of determining the relevant $E_{\text {cat }}^{0}$ values poses erroneous calculations of the TOF. Still, it is worth mentioning some notable efforts made to inspire future systematic investigations.

The group of Manbeck and Fujita has initially investigated the positional effects of phenolic groups on the bipyridine platform in the Re bipyridine-based catalyst by incorporation of $\mathrm{OH}$ groups at the $4,4^{\prime}$ and $6,6^{\prime}$ positions of the bipyridine. ${ }^{[51]}$ Though both complexes show nearly identical electrochemical properties, only the 4,4' substitution was active for $\mathrm{CO}_{2}$ reduction. The authors discovered that in the case of the 4,4' derivative undergoes a reductive electrolytic deprotonation of the ligand upon stepwise reduction, which was proposed to dearomatize the metal bonded doubly reduced 4,4'-dihydroxy-2-2'-bipyridine ligand. Interestingly, the chemically modified Re complex was found to be still a competent catalyst unlike its 6,6 ' congener which was unstable upon the first $\mathrm{CO}_{2}$ to $\mathrm{CO}$ reduction cycle. The group of Nervi has successfully reported a Mn catalyst 24 (Figure 6) having a 4-phenyl-6-(1,3-dihydroxbenzen-2-yl) 2,2'bipyridine ligand having $70 \%$ Faraday efficiency for $\mathrm{CO}$ and log TOF $=0.15$ at $\eta=0.87$ during a controlled potential electrolysis in dry acetonitrile. ${ }^{[54]}$ Significant catalytic current was observed in the presence of $\mathrm{CO}_{2}$ substrate and absence of any exogenous proton source, showing one of the first reported evidence for an intramolecular proton-assisted catalysis from the spatial closeness of pendent phenolic protons to the active site. A 
rhenium analogue with the same ligand showed a diminished electrocatalytic activity suggesting that such local proton source effects are more pronounced for the $\mathrm{Mn}$ analogue. ${ }^{[55]}$ Bocarsly reported similar phenolic functions in a Mn catalyst 25 with 6-(2hydroxyphenol)-2,2'-bipyridine ligand, showing improvement in the activity ( $\log T O F \sim 2.27, \eta=0.44)$ in comparison with the nonfunctionalized $\mathrm{Mn}$ catalyst at similar overpotential and in the absence of any exogenous proton source. ${ }^{[52]}$ Control experiments with methoxy groups showed insignificant catalytic activity, again highlighting the enhancement specifically made by the local phenolic protons during the intramolecular protonation steps. Carboxylic acids have also been dissymmetrically disposed by the group of Cowan in a $\mathrm{Ni}$ cyclam catalyst 26 improved electrocatalytic activity in water $\left(\log T O F_{\max }=3.53, \eta \sim\right.$ $0.85)$ compared to the nonfunctionalized catalyst. The enhanced activity was attributed to its stability and selectivity for $\mathrm{CO}_{2}$ reduction to $\mathrm{CO}$ even at $\mathrm{pH} 2$, overcoming the competitive proton reduction. A bio-inspired approach was even employed in Re-based catalysts by the group of Kubiak by incorporating peptide linkages of varying lengths containing tyrosine residues (a phenol derivative). ${ }^{[57]}$ Molecular dynamics simulation, 2D NMR experiments, and IR spectroelectrochemical experiments showed a stable configuration where the catalyst arm adopts a folded configuration that places the phenol moiety close to the bipyridine ligand, allowing interactions between the pendent proton donating group and the metal-bound substrate.

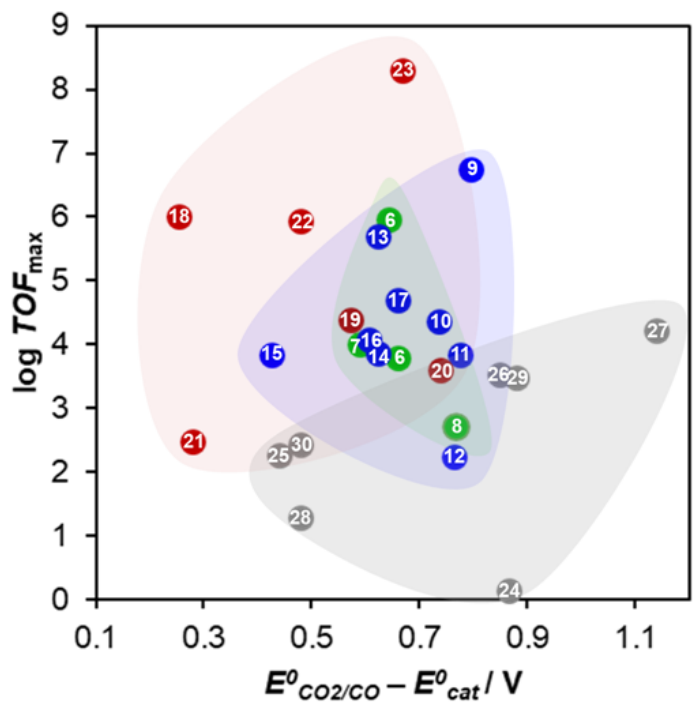

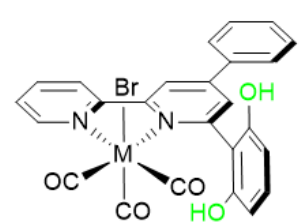

(24) $M=M n$ $M=\operatorname{Re}$

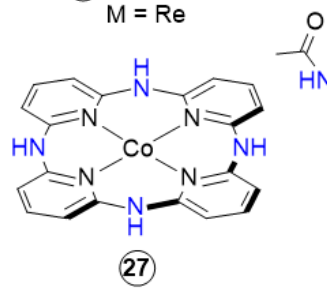

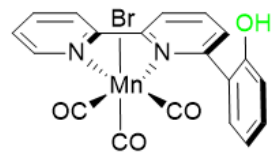<smiles></smiles>

(26)

(25)

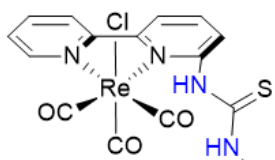

$(29$

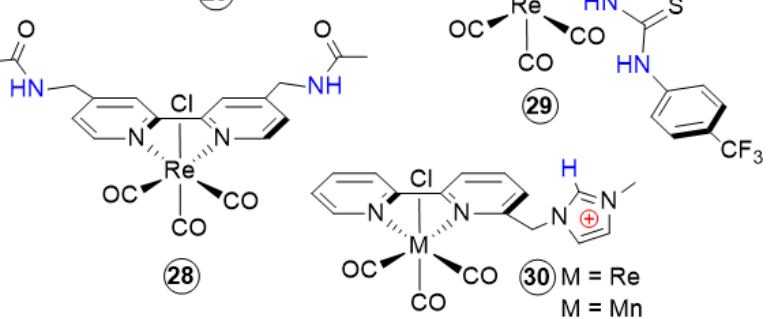

(adsorbed in $\mathrm{Hg}-\mathrm{Au}$ amalgam electrode) ${ }^{[56]}$ which showed

Figure 6. Comparison of the catalytic performance of some notable catalytic systems based on $\mathrm{Re}, \mathrm{Mn}, \mathrm{Ni}$, and Co active sites employing second coordination sphere effects with that of the iron porphyrin system analysed in Figure 4. Numbers correspond to the catalyst structures shown on the right. Experimental conditions are indicated in the text and the electrocatalytic performances are extracted/estimated based on available reported data.

Initial DFT studies on the well-known Ni cyclam catalyst show that a trans $I$ isomer of the catalyst is more favorable in stabilizing a $\mathrm{CO}_{2}$ substrate by hydrogen bonding to the $\mathrm{NH}$ protons of the ligand. ${ }^{[58]}$ This isomer with four cofacial $\mathrm{H}$-atoms is greatly stabilizing the $\mathrm{CO}_{2}$ adduct compared to the trans III isomer (two cofacial $\mathrm{H}$-atoms) by approximately $3 \mathrm{kcal} / \mathrm{mol} .{ }^{[59]} \mathrm{A}$ systematic study was performed by the group of Marinescu on the effect of pendent secondary amines as proton relays on a cobalt pyridine macrocycle and showed a linear dependence on the number of pendent amines in the second coordination sphere. Having four nearby amino groups in catalyst 27 achieved the best performance with log $T O F_{\max }$ of 4.23 in DMF with $1.5 \mathrm{M} \mathrm{TFE} .{ }^{[60,61]}$ Unlike the metal cyclams, the pendent amines lie completely outside the primary coordination sphere of the metal allowing different roles of the amines as proton relays facilitating noncooperative hydrogen bonds with the acids in the solution. However, this improved catalytic activity comes at the cost of high overpotential $(\eta=1.14 \mathrm{~V})$. Kubiak and coll. reported a simple acetamidomethyl group in the 4 positions of the bipyridine ligand of a Re catalyst which shifted the potentials anodically $(220 \mathrm{mV}$ shift for the first reduction and $440 \mathrm{mV}$ shift for the second reduction) compared to the nonfunctionalized catalyst. $^{[57]}$ This positive shift in the potential was similarly observed if two acetamidomethyl groups were incorporated on the $4,4^{\prime}$ positions of the bipyridine ligand in catalyst $28^{[62]}$ The enhancement was mainly attributed to the formation of hydrogen-bonded dimers which catalyze the reductive disproportionation of $\mathrm{CO}_{2}$ to $\mathrm{CO}$ and $\mathrm{CO}_{3}{ }^{2-}$ in a bimolecular mechanistic pathway. Thus, the $\mathrm{H}$-bond donors in the amide moieties do not directly interact with the metal carboxylate intermediate. However, a lower log TOF $\max$ of 1.27 with $\eta \sim 0.48$ $\mathrm{V}$ and $60 \%$ Faraday efficiency for $\mathrm{CO}$ was observed for this mechanism (in ACN and absence of proton source). The group of Neumann has dissymmetrically tethered thiourea functions in the periphery of the Re catalyst 29 achieving log $T O F_{\max }$ of 3.48 with $\eta \sim 0.88 \mathrm{~V}$ in $\mathrm{ACN} .{ }^{[63]}{ }^{1} \mathrm{H}$ NMR measurements showed that the proximal hydrogen atom of the thiourea moiety directly binds to the oxygen atom of the $\mathrm{CO}_{2}$ substrate. In this way, the thiourea group can effectively bind $\mathrm{CO}_{2}$ and stabilize the carboxylate intermediate and at the same time, act as a local proton donor. However, addition of any external proton source (i.e., water) inhibited the catalytic activity of the system, likely interfering with the hydrogen bonding interactions preestablished by the thiourea group on the $\mathrm{CO}_{2}$ adduct.

The group of Nippe combined the synergistic effects of $\mathrm{H}$ bond donors and electrostatic interactions by introducing imidazolium moieties in the periphery of the $\mathrm{Re}$ and $\mathrm{Mn}$ bipyridine catalyst $30^{\left[{ }^{[64,65]}\right.}$ Since this class of catalysts involves the loss of halide during the catalytic cycle, it was proposed that the $\mathrm{C}_{2}-\mathrm{H}$ carbon of the imidazolium moiety interacts with the 
halide promoting its release upon first reduction. Addition of another electron forms the doubly reduced pentacoordinated active species, which in the presence of $\mathrm{CO}_{2}$ forms a metal carboxylic acid intermediate. Subsequent addition of electrons and protons (from a water network) results to a tetra-carbonyl species, which upon reduction and $\mathrm{CO}$ dissociation regenerates the initial reactive species. ${ }^{[65]}$ This resulted in an improved catalytic activity (for the Re derivative, $\log T O F_{\max }=2.44$ and $\eta \sim$ $0.48 \mathrm{~V})$ in $\mathrm{ACN}$ with $2.8 \mathrm{M} \mathrm{H}_{2} \mathrm{O}$ compared to the nonfunctionalized catalyst. In a control experiment, when the imidazolium $\mathrm{C}_{2}-\mathrm{H}$ was replaced with $\mathrm{C}_{2}-\mathrm{CH}_{3}$, the catalytic activity was lower indicating the critical role that $\mathrm{C}_{2}-\mathrm{H}$ plays in the catalytic cycle. ${ }^{[64]}$ Though the overpotentials are lowered for these modified catalysts, the TOF and Faradaic efficiency for CO (77\% for Re and $70 \%$ for $\mathrm{Mn}$ analogue) are still relatively low. Furthermore, addition of higher concentrations of water (beyond $2.8 \mathrm{M}$ ) significantly decreased the activity of the $\mathrm{Re}$ analogue which is usually not observed for the nonfunctionalized catalyst. This is indicative that such strategy inadvertently resulted in major alterations in the mechanistic pathways.

\section{Summary and Outlook}

In this short focus, we exposed some insightful contributions of J-M Savéant and colleagues to provide an appropriate method to analyze the electrocatalytic activity of molecular based complexes for $\mathrm{CO}_{2}$ reduction. The foot-of-the-wave analysis, abbreviated FOWA, is already well anchored in the jargon of chemists involved in molecular electrocatalysis of small molecules transformations. With the catalytic Tafel plots, he set the cardinal zone where chemists must strive to pin the performance of their catalysts while advancing the state of art in the field. With the endeavor to keep the models simple from a synthetic point of view, he has also set the stage on ways to direct the catalytic activity of molecular complexes with different functionalities. The general class of functionalities outlined in the different strategies for second coordination effects discussed herein can easily be perceived to be implemented to other catalytic systems (and even to novel discoveries), inspiring a wave of possibilities for future directions. From the systematic analyses of reactivity-structure trends observe in the iron porphyrin system, the following are some notable directions for intelligent catalyst design:

(i) though countless combinations of second coordination functionalities and catalytic centers can be pursued, smart design still requires careful positioning of these functionalities near the metal carboxylate adduct which can be achieved either by theoretical predictions or by systematic experimental investigation of linker lengths and nature,

(ii) the growing development in ionic liquids ${ }^{[66-70]}$ can inspire various cationic functionalities in the vicinity of the catalytic centers, which shows, by far, the most promise in exalting catalytic performances,

(iii) the emerging use of molecular catalysts performing at levels similar to solid-state catalysts, ${ }^{[71-73]}$ inspires new opportunities into looking how these second coordination sphere effects in molecular catalysts translate to performances in electrochemical reactors (i.e., gas-diffusion electrodes, ${ }^{[73]}$ nanoparticles ${ }^{[74]}$ )

(iv) the increasing interest in heterogenizing molecular catalysts in hybrid interfaces in photo-/electrochemical cells, which at the moment utilizes basic catalytic design units, ${ }^{[23,25]}$ presents interesting prospects for the role of these design intricacies in achieving unbiased production of solar fuels.

There is still a long way ahead for molecular catalysts to reach more highly reduced forms of $\mathrm{CO}_{2}$ with the formation of $\mathrm{C}-\mathrm{C}$ bond products. It makes no doubt that hard challenges are still ahead to comprehend the intimate mechanistic routes both in electro- and photo-driven $\mathrm{CO}_{2}$ reduction catalysis. Efforts must go on to unravel these issues.

Keywords: iron porphyrin • carbon dioxide reduction • electrocatalysis $\cdot$ molecular catalyst $\cdot$ second coordination sphere

[1] C. Costentin, B. Limoges, M. Robert, C. Tard, ACS Catal. 2021, 3224 3238

[2] A. R. Battersby, C. J. R. Fookes, G. W. J. Matcham, E. McDonald Nature 1980, 285, 17-21.

[3] F. A. Walker, U. Simonis, in Encyclopedia of Inorganic Chemistry, American Cancer Society, 2006.

[4] M. Sono, M. P. Roach, E. D. Coulter, J. H. Dawson, Chem. Rev. 1996 96, 2841-2888.

[5] M. Wikström, K. Krab, V. Sharma, Chem. Rev. 2018, 118, 2469-2490.

[6] S. Amanullah, P. Saha, A. Nayek, M. E. Ahmed, A. Dey, Chem. Soc. Rev. 2021, 50, 3755-3823.

[7] C. J. Reed, Q. N. Lam, E. N. Mirts, Y. Lu, Chem. Soc. Rev. 2021, 50, 2486-2539

[8] A. M. Appel, J. E. Bercaw, A. B. Bocarsly, H. Dobbek, D. L. DuBois, M. Dupuis, J. G. Ferry, E. Fujita, R. Hille, P. J. A. Kenis, C. A. Kerfeld, R. H. Morris, C. H. F. Peden, A. R. Portis, S. W. Ragsdale, T. B. Rauchfuss, J. N. H. Reek, L. C. Seefeldt, R. K. Thauer, G. L. Waldrop, Chem. Rev. 2013, 113, 6621-6658.

[9] K. Takahashi, K. Hiratsuka, H. Sasaki, S. Toshima, Chem. Lett. 1979, 8, 305-308.

[10] M. Hammouche, D. Lexa, J. M. Savéant, M. Momenteau, J. Electroanal. Chem. Interfacial Electrochem. 1988, 249, 347-351.

[11] C. Costentin, S. Drouet, G. Passard, M. Robert, J.-M. Savéant, J. Am. Chem. Soc. 2013, 135, 9023-9031.

[12] M. Hammouche, D. Lexa, M. Momenteau, J. M. Saveant, J. Am. Chem. Soc. 1991, 113, 8455-8466.

[13] I. Bhugun, D. Lexa, J.-M. Saveant, J. Am. Chem. Soc. 1994, 116 5015-5016

[14] I. Bhugun, D. Lexa, J.-M. Savéant, J. Am. Chem. Soc. 1996, 118 1769-1776

[15] C. Costentin, S. Drouet, M. Robert, J.-M. Savéant, J. Am. Chem. Soc 2012, 134, 11235-11242.

[16] C. Costentin, M. Robert, J.-M. Savéant, Chem. Soc. Rev. 2013, 42 2423-2436.

[17] C. Costentin, G. Passard, J.-M. Savéant, J. Am. Chem. Soc. 2015, 137, 5461-5467.

[18] C. Costentin, J.-M. Savéant, ChemElectroChem 2014, 1, 1226-1236.

[19] C. Costentin, J.-M. Savéant, Nat. Rev. Chem. 2017, 1, 0087.

[20] N. Elgrishi, M. B. Chambers, X. Wang, M. Fontecave, Chem. Soc. Rev. 2017, 46, 761-796.

[21] H. Takeda, C. Cometto, O. Ishitani, M. Robert, ACS Catal. 2017, 7, 7088.

[22] R. Francke, B. Schille, M. Roemelt, Chem. Rev. 2018, 118, 4631-4701.

[23] K. E. Dalle, J. Warnan, J. J. Leung, B. Reuillard, I. S. Karmel, E. Reisner, Chem. Rev. 2019, 119, 2752-2875.

[24] C. Jiang, A. W. Nichols, C. W. Machan, Dalton Trans. 2019, 48, 9454 9468.

[25] P. Gotico, Z. Halime, A. Aukauloo, Dalton Trans. 2020, 49, 2381-2396.

[26] C. Costentin, S. Drouet, M. Robert, J.-M. Savéant, Science 2012, 338, 90-94.

[27] C. Costentin, G. Passard, M. Robert, J.-M. Savéant, Proc. Natl. Acad Sci. USA 2014, 111, 14990-14994. 
[28] C. Costentin, M. Robert, J.-M. Savéant, A. Tatin, Proc. Natl. Acad. Sci. USA 2015, 112, 6882-6886.

[29] I. Azcarate, C. Costentin, M. Robert, J.-M. Savéant, J. Phys. Chem. C 2016, 120, 28951-28960.

[30] I. Azcarate, C. Costentin, M. Robert, J.-M. Savéant, J. Am. Chem. Soc. 2016, 138, 16639-16644.

[31] P. Gotico, B. Boitrel, R. Guillot, M. Sircoglou, A. Quaranta, Z. Halime, W. Leibl, A. Aukauloo, Angew. Chem. Int. Ed 2019, 58, 4504-4509.

[32] P. Gotico, L. Roupnel, R. Guillot, M. Sircoglou, W. Leibl, Z. Halime, A. Aukauloo, Angew. Chem. Int. Ed 2020, 59, 22451-22455.

[33] A. Khadhraoui, P. Gotico, B. Boitrel, W. Leibl, Z. Halime, A. Aukauloo, Chem. Commun. 2018, 54, 11630-11633.

[34] A. Khadhraoui, P. Gotico, W. Leibl, Z. Halime, A. Aukauloo, ChemSusChem 2021, 14, 1308-1315.

[35] J.-H. Jeoung, H. Dobbek, Science 2007, 318, 1461.

[36] C. G. Margarit, C. Schnedermann, N. G. Asimow, D. G. Nocera, Organometallics 2019, 38, 1219-1223.

[37] A. J. Libbey, J. T. Stock, Anal. Chem. 1970, 42, 526-529.

[38] P. Sen, B. Mondal, D. Saha, A. Rana, A. Dey, Dalton Trans. 2019, 48, 5965-5977.

[39] C. Römelt, J. Song, M. Tarrago, J. A. Rees, M. van Gastel, T. Weyhermüller, S. DeBeer, E. Bill, F. Neese, S. Ye, Inorg. Chem. 2017 $56,4745-4750$.

[40] C. Römelt, S. Ye, E. Bill, T. Weyhermüller, M. van Gastel, F. Neese, Inorg. Chem. 2018, 57, 2141-2148.

[41] U. Manna, S. Kayal, S. Samanta, G. Das, Dalton Trans. 2017, 46, 10374-10386.

[42] E. M. Nichols, C. J. Chang, Organometallics 2018, 38, 1213-1218.

[43] C. K. Williams, A. Lashgari, J. A. Tomb, J. Chai, J. J. Jiang, ChemCatChem 2020, 12, 4886-4892.

[44] N. Devi, C. K. Williams, A. Chaturvedi, J. "Jimmy" Jiang, ACS Appl. Energy Mater. 2021, DOI 10.1021/acsaem.1c00027.

[45] C. K. Williams, A. Lashgari, J. Chai, J. “Jimmy” Jiang, ChemSusChem 2020, 13, 3412-3417.

[46] C. G. Margarit, N. G. Asimow, M. I. Gonzalez, D. G. Nocera, J. Phys. Chem. Lett. 2020, 11, 1890-1895.

[47] B. A. Rosen, A. Salehi-Khojin, M. R. Thorson, W. Zhu, D. T. Whipple, P. J. A. Kenis, R. I. Masel, Science 2011, 334, 643-644.

[48] A. Warshel, PNAS 1978, 75, 5250-5254.

[49] A. Warshel, Acc. Chem. Res. 1981, 14, 284-290.

[50] P. K. Sharma, Z. T. Chu, M. H. M. Olsson, A. Warshel, PNAS 2007, 104, 9661-9666.

[51] G. F. Manbeck, J. T. Muckerman, D. J. Szalda, Y. Himeda, E. Fujita, J. Phys. Chem. B 2015, 119, 7457-7466.

[52] J. Agarwal, T. W. Shaw, H. F. Schaefer, A. B. Bocarsly, Inorg. Chem. 2015, 54, 5285-5294.

[53] M. L. Clark, P. L. Cheung, M. Lessio, E. A. Carter, C. P. Kubiak, ACS Catal. 2018, 8, 2021-2029.

[54] F. Franco, C. Cometto, F. F. Vallana, F. Sordello, E. Priola, C. Minero, C. Nervi, R. Gobetto, Chem. Commun. 2014, 50, 14670-14673.

[55] L. Rotundo, C. Garino, E. Priola, D. Sassone, H. Rao, B. Ma, M. Robert, J. Fiedler, R. Gobetto, C. Nervi, Organometallics 2019, 38, 1351-1360.

[56] G. Neri, I. M. Aldous, J. J. Walsh, L. J. Hardwick, A. J. Cowan, Chem. Sci. 2016, 7, 1521-1526.

[57] S. A. Chabolla, C. W. Machan, J. Yin, E. A. Dellamary, S. Sahu, N. C. Gianneschi, M. K. Gilson, F. A. Tezcan, C. P. Kubiak, Faraday Discuss. 2017, 198, 279-300.

[58] J. D. Froehlich, C. P. Kubiak, Inorg. Chem. 2012, 51, 3932-3934.

[59] J. Song, E. L. Klein, F. Neese, S. Ye, Inorg. Chem. 2014, 53, 75007507.

[60] A. Chapovetsky, T. H. Do, R. Haiges, M. K. Takase, S. C. Marinescu, J. Am. Chem. Soc. 2016, 138, 5765-5768.

[61] A. Chapovetsky, M. Welborn, J. M. Luna, R. Haiges, T. F. Miller, S. C. Marinescu, ACS Cent. Sci. 2018, 4, 397-404.

[62] C. W. Machan, S. A. Chabolla, J. Yin, M. K. Gilson, F. A. Tezcan, C. P. Kubiak, J. Am. Chem. Soc. 2014, 136, 14598-14607.

[63] E. Haviv, D. Azaiza-Dabbah, R. Carmieli, L. Avram, J. M. L. Martin, R. Neumann, J. Am. Chem. Soc. 2018, 140, 12451-12456.

[64] S. Sung, D. Kumar, M. Gil-Sepulcre, M. Nippe, J. Am. Chem. Soc. 2017 139, 13993-13996.
[65] S. Sung, X. Li, L. M. Wolf, J. R. Meeder, N. S. Bhuvanesh, K. A. Grice, J. A. Panetier, M. Nippe, J. Am. Chem. Soc. 2019, 141, 6569-6582.

[66] M. Watanabe, M. L. Thomas, S. Zhang, K. Ueno, T. Yasuda, K. Dokko, Chem. Rev. 2017, 117, 7190-7239.

[67] S. Zhang, J. Zhang, Y. Zhang, Y. Deng, Chem. Rev. 2017, 117, 67556833

[68] E. Vichou, Y. Li, M. Gomez-Mingot, M. Fontecave, C. M. SánchezSánchez, J. Phys. Chem. C 2020, 124, 23764-23772.

[69] Y. Oh, X. Hu, Chem. Soc. Rev. 2013, 42, 2253-2261.

[70] J. Lin, Z. Ding, Y. Hou, X. Wang, Scientific Reports 2013, 3, 1056.

[71] S. Ren, D. Joulié, D. Salvatore, K. Torbensen, M. Wang, M. Robert, C. P. Berlinguette, Science 2019, 365, 367-369.

[72] K. Torbensen, D. Joulié, S. Ren, M. Wang, D. Salvatore, C. P Berlinguette, M. Robert, ACS Energy Lett. 2020, 5, 1512-1518.

[73] K. Torbensen, C. Han, B. Boudy, N. von Wolff, C. Bertail, W. Braun, M. Robert, Chemistry - A European Journal 2020, 26, 3034-3038.

[74] Z. Cao, S. B. Zacate, X. Sun, J. Liu, E. M. Hale, W. P. Carson, S. B. Tyndall, J. Xu, X. Liu, X. Liu, C. Song, J. Luo, M.-J. Cheng, X. Wen, W. Liu, Angewandte Chemie International Edition 2018, 57, 12675-12679.

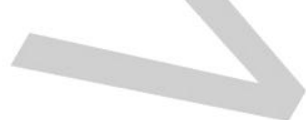

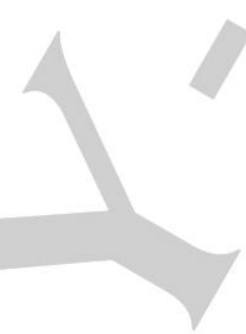




\section{Entry for the Table of Contents}

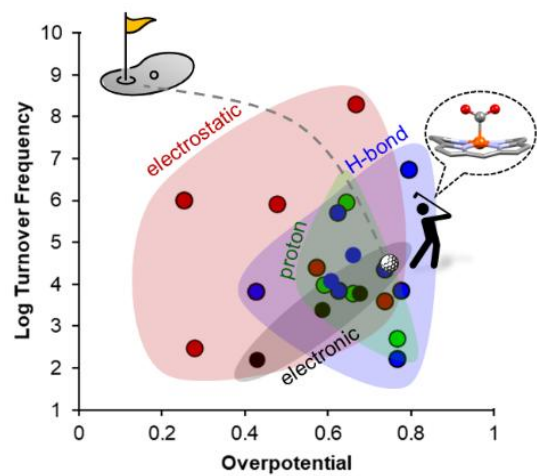

Eyes on the Goal! Prof. J-M Savéant has set a stage for performance benchmarking of molecular electrocatalysts for carbon dioxide reduction and importantly established catalyst design principles for catalysis improvement. In this Minireview, we highlight how his seminal works have inspired chemists to continually optimize iron porphyrins in terms of efficiency, robustness, and selectivity.

Institute and/or researcher Twitter usernames: @CEA_Joliot, @I2BCParisSaclay, @UnivParisSaclay 